\title{
Author Spotlight: Luigi Colecchia
}

\section{Luigi Colecchia ${ }^{1}$}

Published online: 8 February 2020

(c) Springer Science+Business Media, LLC, part of Springer Nature 2020

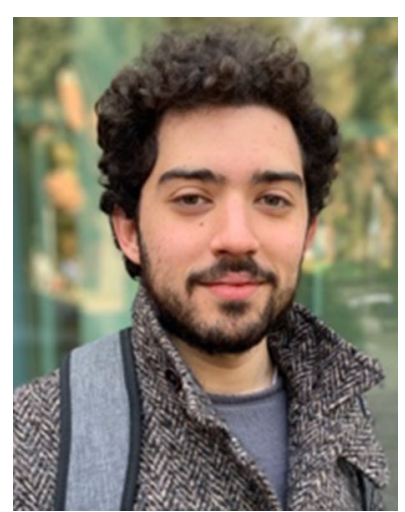

Luigi Colecchia
Luigi Colecchia is currently a third-year student of the English Medical School of the University of Bologna (UniBo). He has two high school diplomas: with one from Italy and another from Canada. He will graduate from medical school in June 2023. He is interested in the study of cancer in the field of internal medicine. He is a leader of the local medical students' association.

Publisher's Note Springer Nature remains neutral with regard to jurisdictional claims in published maps and institutional affiliations.

Luigi Colecchia

luigi.colecchia@studio.unibo.it

1 University of Bologna, Bologna, Italy 